\title{
Author Correction: Direct characterization of cis-regulatory elements and functional dissection of complex genetic associations using HCR-FlowFISH
}

Steven K. Reilly (D), Sager J. Gosai (D), Alan Gutierrez, Ava Mackay-Smith D, Jacob C. Ulirsch (D), Masahiro Kanai (D), Kousuke Mouri (D), Daniel Berenzy, Susan Kales, Gina M. Butler, Adrianne Gladden-Young, Redwan M. Bhuiyan (D), Michael L. Stitzel (D), Hilary K. Finucane (iD, Pardis C. Sabeti (D) and Ryan Tewhey (iD)

Correction to: Nature Genetics https://doi.org/10.1038/s41588-021-00900-4, published online 29 July 2021.

In the version of this Article initially published, there was an error in the SNP number shown. In Figure 3b, the center label "rs1546273" should have read "rs1546723," and in the third paragraph of the section titled "Comprehensive CRE scans of five loci show the flexibility of HCR-FlowFISH," in the sentence beginning "At the $-77 \mathrm{~kb}$ CRE," the identifier "rs1546273" should have read "rs1546723." The errors have been corrected in the online version of the paper.

Published online: 8 September 2021

https://doi.org/10.1038/s41588-021-00943-7

( ) The Author(s), under exclusive licence to Springer Nature America, Inc. 2021 